\title{
Environmental context effects of background color in free recall
}

\author{
TAKEO ISARIDA \\ Shizuoka University, Hamamatsu, Japan \\ AND \\ TOSHIKO K. ISARIDA \\ Shizuoka Prefectural University, Shizuoka, Japan
}

\begin{abstract}
In four experiments, we investigated background-color context effects in free recall. A total of 194 undergraduates studied words presented one by one against a background color, and oral free recall was tested after a 30 -sec filled retention interval. A signal for recall was presented against a background color throughout the test. Recalled items were classified as same- and different-context items according to whether the background colors at study and test were the same or different. Significant context effects were found in Experiments 1 and 2, in which two background colors were randomly alternated word by word. No context effects were found in Experiments 3 and 4, in which a common background color was presented for all items (Experiment 3) or for a number of successive items (Experiment 4). The results indicate that a change in background colors is necessary and sufficient to produce context effects. Implications of the present findings are discussed.
\end{abstract}

Environmental context (EC) refers to incidental information about the environment in which the focal information is processed. The EC is encoded with the focal information into an episodic memory trace and is used as a retrieval cue at the time of remembering. Clarifying the functions of the EC is essential for understanding episodic memory processes. The majority of EC studies have used a variety of places (physical locations, see, e.g., Godden \& Baddeley, 1975; Smith, Glenberg, \& Bjork, 1978). However, EC studies have also used other environmental features, such as background color (e.g., Isarida, Isarida, \& Okamoto, 2005; Rutherford, 2004; Weiss \& Margolius, 1954), a combination of visual features of a computer screen called simple visual context (e.g., Dougal \& Rotello, 1999; Murnane \& Phelps, 1993, 1994, 1995), background music (e.g., Balch, Bowman, \& Mohler, 1992; Smith, 1985), voice (e.g., Geiselman \& Bjork, 1980; Geiselman \& Glenny, 1977), posture (Rand \& Wapner, 1967), and odor (e.g., Cann \& Ross, 1989; Pointer \& Bond, 1998).

There are still unanswered questions about the nature of EC. Smith and Vela (2001) demonstrated the reliability of EC-dependent memory in a meta-analysis. However, for theoretical reasons, they excluded such contexts as background color, simple visual context, voice, posture, and odor from their meta-analysis. Presently, there is no empirical evidence demonstrating that the contexts that they included are functionally different from those that were not included. Empirical research is needed to clarify the functioning of various types of EC and, if necessary, to classify its types.

The present study focuses on the context effects of background color. Background color can be the environmental information that is most contiguous with the focal information, such as to-be-remembered (TBR) items. Background color always exists in a learner's visual field, whether he or she is aware of it or not. Especially when a learner concentrates on studying TBR items, only an item and its background color can be seen. If every type of EC were associated with focal information by contiguity, then background color should produce the strongest context effect.

However, previous findings are inconsistent with this prediction. The background-color context effect may be weaker than the effect of other ECs, or the contextual function of background color may be different from other ECs. A phenomenon that may be specific to backgroundcolor context is that no context effects are found when all TBR items are presented against one common background color. Paired-associate studies have found significant context effects with different background colors for respective pairs (Dulsky, 1935; Weiss \& Margolius, 1954), but no effects with a common background color for all pairs (Dulsky, 1935; Petrich \& Chiesi, 1976). Pointer and Bond (1998) found no context effect for sentence recall when the TBR sentences were printed on one differently colored sheet of paper, whereas odor perfuming the sheet produced a significant context effect (Pointer \& Bond, 1998). Rutherford (2004) compared $A^{\prime}$ (a recognition-

T. Isarida, isarida@inf.shizuoka.ac.jp 
discrimination measure) between conditions where all TBR items were presented against one background color versus one of three background colors. The results showed a context effect for the three-color condition but no effect for the one-color condition. In contrast, most ECs, such as place, odor, and background music, can produce context effects when only one context surrounds all TBR items. Thus, a weaker effect or a different function of background-color context conflicts with the prediction that background color should produce the strongest context effect in various types of contexts because it has such a high contiguity.

Rutherford (2004) explained the lack of an effect of background-color context when all TBR items were presented against one common background color in terms of cue overload (Watkins \& Watkins, 1975). All the TBR items could have overloaded the one contextual cue of background color, whereas each of the three contextual cues of different background colors would not have been overloaded by only one third of the items. However, there is another difference between the one and three background-color conditions in Rutherford (2004). In the three-color condition, the background colors must change item-by-item, because each TBR item is presented against one of the three background colors. In the one-color condition, the background color cannot change item-by-item, because there is only one background color. Thus, Rutherford's null effect in the one-color condition can be explained in two ways. On the one hand, the null effect could be caused by cue overload as Rutherford explained. On the other hand, the null effect could be caused by the persistence of one background color. If background colors changed item-by-item, then a significant context effect would appear. Furthermore, in the other studies in which no context effects were found with one background color (Dulsky, 1935; Petrich \& Chiesi, 1976; Pointer \& Bond, 1998), it is also unclear whether the effects were eliminated by cue overload, the persistence of one color, or both. For example, the memory load of the TBR sentence used in Pointer and Bond (1998) might have been large enough to lead to cue overload. However, the paired associate studies (Dulsky, 1935; Petrich \& Chiesi, 1976) used 10 nonsense-syllable pairs, which were not likely to lead to cue overload.

Recently, Isarida and his colleagues found that background-color context effects in recognition discrimination appeared when six background colors were used, but disappeared when two colors were used (Isarida et al., 2005; Isarida \& Ozeki, 2005). In these studies, background colors changed item-by-item in both conditions, and the two-color condition was more likely to be overloaded than the six-color condition. These results suggest that cue overload might determine the background-color context effects, even if background colors are changed item-by-item. However, it has not yet been demonstrated that the background-color context effect is exclusively determined by cue overload. In other words, it is still not known whether an item-by-item change in background colors is necessary to produce background-color context effects, even when the cues are not overloaded.
The primary purpose of the present study was to examine whether an item-by-item change in background colors is necessary for producing context effects in recall when the number of TBR items per context is not large enough to lead to cue overload. For this purpose, the number of TBR items that can associate with each background color was limited to 15 in the present free-recall experiments. Godden and Baddeley (1975) used 36 items per context in their free-recall experiment and found a clear context effect. Isarida and his colleagues have used no more than 20 items per context in a number of free-recall experiments and have consistently found clear context effects (Isarida, 1992, 2005; Isarida \& Isarida, 1999, 2004, 2006; Isarida $\&$ Morii, 1986). Thus, the list length of 15 items per context should be short enough to avoid cue overload.

The secondary purpose of the present study was to observe the possible influence of time for studying items (study time) on the effect size of the background-color context. In the case of place context, the size of the EC effect in free recall was found to increase as a function of study time (Isarida, 2005) and number of rehearsals (Isarida, 1992). However, an unchanged effect size in free recall for different study times was found for background-music context (Isarida \& Isarida, 2005). Accordingly, the present study examined whether the effect size increases (as was found for place context), does not change (as was found for background-music context), or decreases with study time.

The present experiments used an uncued free-recall paradigm. There were two reasons for using this paradigm. One was to measure the context effect clearly. The pairedassociate (Dulsky, 1935; Petrich \& Chiesi, 1976; Weiss \& Margolius, 1954) and recognition paradigms (Isarida et al., 2005; Isarida \& Ozeki, 2005; Rutherford, 2004) used in the majority of the preceding studies are unfavorable for observing EC effects. Because explicit cues like stimulus terms in paired associates and item cues in recognition are much stronger than EC cues, they can weaken or change the EC-dependent phenomena (see, e.g., Smith, 1988, 1994). Moreover, associative processing of paired associates reduces - and often eliminates - EC effects (cf. Smith \& Vela, 2001).

The other reason for using free recall was to observe output order in free-recall protocols, as well as the accuracy of recall. The first response is cued only by the context, whereas the subsequent responses are cued by interitem relational information, as well as the context (Isarida, 2005). At the same time, the subsequent responses can also be inhibited by output interference. Accordingly, the present experiments analyzed free-recall protocols using the number of first responses, mean output percentile, and clustering related to the background colors against which the TBR items were presented at study. In the case of place context, the items within the list should be related and/ or compete with each other. More specifically, the first few responses in free recall characterized, the contextdependent recency effect (Isarida \& Isarida, 2006), and output interference inhibited the subsequent responses (Isarida, 1989). Furthermore, each first response from the subjectively organized clusters was found to reflect the context-dependent study-time effect more purely than 
the subsequent responses (Isarida, 2005). If backgroundcolor context had the same function as place context, a relationship and/or competition among responses in free recall would be found.

\section{EXPERIMENT 1}

Experiment 1 examined whether a background-color context effect would appear if two background colors were randomly changed item-by-item. The number of items per background color was 12 , which was expected to avoid cue overload. Experiment 1 also examined whether the effect size of background-color context would increase, decrease, or not change as a function of study time, provided that significant context effects occurred. The present experiments manipulated the study time by varying the presentation rate. Free-recall data were analyzed not only for the proportion of correct recall, but also by the number of first responses in recall, by output percentile, and by clustering related to background colors.

\section{Method}

Design. A $2 \times 2$ mixed factorial design was used. The first factor was context - same context (SC) or different context (DC) - as the within-subjects factor. The second factor was presentation rate (3 or $6 \mathrm{sec} /$ item) as the between-subjects factor.

Participants. The participants were 32 undergraduates who were enrolled in an introductory psychology course at Shizuoka University, Hamamatsu, Japan, and 32 undergraduates enrolled in a developmental psychology course at Shizuoka Prefectural University, Shizuoka, Japan. They received extra course credit for their participation. They were randomly assigned to one of the two betweensubjects conditions. The 3 -sec condition consisted of 16 Shizuoka University and 16 Shizuoka Prefectural University undergraduates, and the 6-sec condition consisted of 16 Shizuoka University and 16 Shizuoka Prefectural University undergraduates.

Materials. TBR items were 24 unrelated Japanese two-letter words whose association values (Hayashi, 1976) were not less than 90.

Background color. A pair of background colors was randomly selected from two pairs (light red and light green, or light yellow and light blue), with the restriction that half of the participants received light red and light green and the other half received light yellow and light blue.

Procedure. All the participants individually participated in the 15-min experiment. TBR items were presented one-by-one at a rate of $3 \mathrm{sec}$ (exposure time was $2.5 \mathrm{sec}$ ) or $6 \mathrm{sec}$ (exposure time was $5.5 \mathrm{sec}$ ) per item on a 17 -in. computer screen in black 72-point MS-Gothic font. The two background colors randomly changed item-by-item, with the restrictions that no more than three successive background colors were the same and that the two colors were presented the same number of times. The presentation order of items was randomized across participants. Participants were required to study the items and were also instructed that it was not necessary to remember the background color of each item.

Immediately after the presentation of the last item, a random three-digit number was presented in black against a neutral-gray background color. Participants were required to count back orally by threes from the number for $30 \mathrm{sec}$. Following the counting, the signal "???" was presented in black against one of the background colors that was presented at the study session. This test background color was selected randomly from the pairs, with the restriction that the selected presentation times of the items within the pair were the same. Participants were required to orally recall the items in any order for $60 \mathrm{sec}$. The signal and background color were presented throughout this test period. Participants were not particularly required to look at
Table 1

Proportion of Items Recalled and Mean Output Percentile As a Function of Context $\times$ Presentation Rate in Experiment 1

\begin{tabular}{ccccccc}
\hline & \multicolumn{3}{c}{$\begin{array}{c}\text { Proportion of } \\
\text { Items Recalled }\end{array}$} & & \multicolumn{3}{c}{ Output Percentile } \\
\cline { 5 - 6 } Presentation Rate & $M$ & $S D$ & & $M$ & $S D$ & $n$ \\
\hline 3 sec/item & & & & & \\
Same & .417 & .112 & & 49.0 & 12.4 & 32 \\
Different & .333 & .144 & & 54.6 & 14.7 & 31 \\
6 sec/item & & & & & \\
$\quad$ Same & .500 & .168 & & 48.8 & 9.6 & 32 \\
Different & .451 & .144 & & 53.7 & 12.2 & 32 \\
\hline
\end{tabular}

the computer screen throughout the test period. Following the test, participants completed an introspective questionnaire about their encoding and retrieval strategies.

\section{Results}

A $2 \times 2 \times 2$ (context $\times$ presentation rate $\times$ university) ANOVA was computed. The factor of university was used in this analysis to test the homogeneity of participants between the universities (Shizuoka University vs. Shizuoka Prefectural University). The main effects of context $\left[F(1,60)=9.84, M S_{\mathrm{e}}=2.06, p<.01\right]$ and presentation rate $\left[F(1,60)=11.09, M S_{\mathrm{e}}=4.17, p<.01\right]$ were significant, but their interaction was not significant $(F<1)$. Neither the main effect of university nor interactions involving university were significant $(F \mathrm{~s}<1)$. Table 1 shows the mean number of items recalled as a function of the context $\times$ presentation rate.

The numbers of first responses in free recall for the SC and DC conditions were 14 and 18 in the 3 -sec condition and 19 and 13 in the 6-sec condition, respectively. The difference in the number of first responses between the $\mathrm{SC}$ and DC conditions was not significant for the 3 -sec condition $\left[\chi^{2}(1)=0.44, p>.50\right]$ or the 6 -sec condition $\left[\chi^{2}(1)=1.12, p>.20\right]$. Table 1 shows the mean output percentile as a function of the context $\times$ presentation rate. The difference between the SC and DC conditions was not significant for either the $3-\sec [t(61)=1.61, p>.10]$ or the $6-\sec [t(31)=1.28, p>.20]$ condition. As shown in Table 1, the sample size for the 3-sec and DC condition was less than 32, the number of assigned participants. This is because 1 participant recalled only SC items; hence, no output percentile was obtained.

Table 2 shows the observed and expected values of context repetitions, which are the number of times that two items presented against the same background color at study appear adjacently in a recall protocol. The difference between the observed and expected values of context repetitions was not significant for the 3 -sec condition $[t(31)=$ $\left.1.01, M S_{\mathrm{e}}=1.23, p>.20\right]$ or the 6-sec condition $(t<1)$.

On the questionnaire, participants reported having looked at the computer screen for most of the test period. Only 2 participants reported that they had intentionally used the background colors to encode and/or to retrieve items. These 2 participants did not show any context effect: One participant recalled five SC items and five DC items; the other recalled six SC items and six DC items. 
Table 2

Observed and Expected Values of Context Repetitions in Free

Recall As a Function of Presentation Rate in Experiment 1

\begin{tabular}{cccccc}
\hline & \multicolumn{2}{c}{ Observed } & & \multicolumn{2}{c}{ Expected } \\
\cline { 2 - 3 } \cline { 5 - 6 } Presentation Rate & $M$ & $S D$ & & $M$ & $S D$ \\
\hline 3 sec/item & 3.72 & 1.79 & & 3.96 & 1.24 \\
6 sec/item & 5.22 & 1.93 & & 5.02 & 1.59 \\
\hline
\end{tabular}

\section{Discussion}

The results of Experiment 1 show that items presented against the same background color at both study and test times were recalled more frequently than those presented against different background colors at study and test times, when the two background colors were randomly changed item-by-item at the study time. Statistically, the main effect of context was significant with no interaction of context and presentation rate. This finding implies that the context effect in recall does not require different background colors for respective items, but only a simple item-by-item change between two colors.

The results for the number of first responses and mean output percentile show that SC items were recalled neither first nor earlier. Additionally, the results for context repetition show that responses in recall were not clustered by contexts. Furthermore, the effect size of the backgroundcolor context did not change as a function of presentation rate. The interaction between the factors of context and presentation rate was not significant. The questionnaires indicated that the background-color context effects were produced by unintentional processing.

Note that there has been no other research on background-color context effects in free recall. Thus, the reliability of the present results needs to be confirmed by replication. Furthermore, in Experiment 1, the study-time effect could be confounded with context familiarity, because both the total exposure time of each context (which is a determinant of context familiarity) and each item's presentation time against its background color increased as a function of the presentation rate. Thus, the study time effect should be measured separately from the context familiarity effect.

\section{EXPERIMENT 2}

The primary purpose of Experiment 2 was to replicate the results of Experiment 1. Hence, the main design of Experiment 2 is identical to that of Experiment 1. First, only two background colors were randomly changed item-by-item. Second, the presentation-rate condition was crossed with the context condition. Third, free-recall data were analyzed not only for accuracy of recall but also for interitem relationships and competition in terms of background colors. The secondary purpose of Experiment 2 was to measure the study-time effect separately from the context-familiarity effect.

In Experiment 2, the presentation rate and background color were manipulated as follows: (1) Two lists were used; (2) half of the participants were presented one list at a slow presentation rate and the other list at a fast pre- sentation rate (Group SF), and vice versa for the other half (Group FS); (3) two background colors were presented for both lists; (4) each of the two background colors was also presented at test once serially for the same duration of time; and (5) the effect of presentation rate (study time) was compared between the two groups (Groups SF and FS) for the first and second lists. Consequently, the presentation rate was treated as a between-subjects factor.

As a result of these manipulations, at the beginning of the test for the first list, the study-time effect would be confounded with the context familiarity effect, as was the case in Experiment 1. That is, the total exposure time to a background color is different between Groups FS (fast presentation rate of the first list) and SF (slow presentation rate of the first list) at the beginning of the test for the first list. Consequently, fast-presented items are presented against a less familiar background color, whereas slow-presented items are presented against a more familiar background color. On the other hand, at the beginning of the test for the second list, the confounding factor is eliminated. This is because the difference between Groups FS and SF in total exposure times, which existed at the beginning of the test for the first list, was compensated for by the exposures of the background colors during the presentation of the second list and at the test for the first list.

\section{Method}

Design. A $2 \times 2 \times 2$ mixed design was used. The first factor was context (SC or DC) as a within-subjects factor. The second factor was presentation rate $(1.5$ or $3.0 \mathrm{sec} /$ item $)$ as a between-subjects factor. The third factor was list (first or second list) as a withinsubjects factor.

Participants. The participants were 40 undergraduates who were enrolled in an introductory psychology course at Shizuoka University, Hamamatsu, Japan. None had participated in Experiment 1 . They received extra course credit for their participation. They were randomly assigned to one of the two between-subjects conditions: Group FS or Group SF. Each condition consisted of 20 participants.

Materials. TBR items were 40 unrelated Japanese two-letter words whose association values (Hayashi, 1976) were not less than 90. The 40 items were randomly assigned to two TBR lists.

Background color. A pair of background colors, randomly selected from the two pairs of colors used in Experiment 1, was used for both lists.

Procedure. All the participants individually participated in the 20-min experiment. They received two TBR lists of 20 items. Group FS received the first list at a rate of $1.5 \mathrm{sec} /$ item (exposure time was $1.0 \mathrm{sec}$ ) and the second list at a rate of $3.0 \mathrm{sec} /$ item (exposure time was $2.5 \mathrm{sec}$ ), and the reverse for Group SF. Each TBR item was presented against one of the two background colors. The two background colors changed randomly item-by-item, with the restrictions that no more than three successive background colors were the same and that the two colors were presented the same number of times, as had occurred in Experiment 1. The presentation order of items within the lists was randomized across participants. Following each list presentation, a 30-sec counting task was conducted, as in Experiment 1 , before an 80 -sec oral free-recall task. The signal for recall was presented in black on one of the background colors presented at the study session for the first $40 \mathrm{sec}$, and then the background color was switched to the other color presented at the study session for the last $40 \mathrm{sec}$. The presentation order of the test colors was counterbalanced across participants. A 10-sec break was imposed between the first and second lists. Otherwise, the procedure was identical to that of Experiment 1. 
Table 3

Proportion of Items Recalled As a Function of Context $x$ Presentation Rate $\times$ List in Experiment 2

\begin{tabular}{|c|c|c|c|c|c|c|}
\hline \multirow[b]{3}{*}{ Presentation Rate } & \multicolumn{6}{|c|}{ List } \\
\hline & \multicolumn{2}{|c|}{ First } & \multicolumn{2}{|c|}{ Second } & \multicolumn{2}{|c|}{ Combined } \\
\hline & $M$ & $S D$ & $M$ & $S D$ & $M$ & $S D$ \\
\hline \multicolumn{7}{|l|}{$1.5 \mathrm{sec} /$ item } \\
\hline Same & .405 & .107 & .405 & .132 & .405 & .085 \\
\hline Different & .305 & .188 & .280 & .175 & .293 & .120 \\
\hline \multicolumn{7}{|l|}{$3.0 \mathrm{sec} /$ item } \\
\hline Same & .540 & .132 & .490 & .151 & .515 & .415 \\
\hline Different & .450 & .177 & .380 & .133 & .415 & .114 \\
\hline
\end{tabular}

\section{Results}

Table 3 shows the mean number of items recalled as a function of context $\times$ presentation rate $\times$ list. A $2 \times$ $2 \times 2$ (context $\times$ presentation rate $\times$ list) ANOVA was computed. The main effects of context $[F(1,38)=17.59$, $\left.M S_{\mathrm{e}}=2.57, p<.001\right]$ and presentation rate $[F(1,38)=$ $\left.12.69, M S_{\mathrm{e}}=4.26, p<.01\right]$ were significant, but that of list was not significant $\left[F(1,38)=1.32, M S_{\mathrm{e}}=3.97\right]$. No interactions were significant $(F \mathrm{~s}<1)$.

Table 4 shows the numbers of first responses in free recall for the SC and DC conditions as a function of context $\times$ presentation rate $\times$ list. The differences in the numbers of first responses between the SC and DC conditions were not significant for the 1.5 -sec and first list condition $\left[\chi^{2}(1)=0.80, p>.30\right]$, the 3.0 -sec and first list condition $\left[\chi^{2}(1)=0.20, p>.60\right]$, the 1.5 -sec and second list condition $\left[\chi^{2}(1)=0.20, p>.60\right]$, or the 3.0 -sec and second list condition $\left[\chi^{2}(1)=0\right]$. Table 4 also shows the mean output percentile as a function of context $\times$ presentation rate $\times$ list. The difference between the SC and DC conditions was not significant for the $1.5-\mathrm{sec}$ and first list condition $[t(37)=1.61, p>.10]$, the 3.0-sec and first list condition $(t<1)$, the 1.5 -sec and second list condition $(t<1)$, or the 3.0-sec and second list condition $(t<1)$. As shown in Table 4, the sample sizes in the 1.5-sec and DC condition were less than the number of assigned participants, because one or more participants recalled only SC items; hence, no output percentile was obtained.

The observed and expected values for the number of context repetitions of items in recall are shown in Table 5. The difference between the observed and expected values for context repetitions was not significant for the 1.5 -sec and first list condition $\left[t(19)=1.16, M S_{\mathrm{e}}=0.25, p>.20\right]$, the $3.0-\mathrm{sec}$ and first list condition $\left[t(19)=1.00, M S_{\mathrm{e}}=0.34\right.$, $p>.30]$, the 1.5 -sec and second list condition $(t<1)$, or the 3.0-sec and second list condition $(t<1)$.

On the questionnaire, participants reported that they looked at the computer screen for most of the test period. Only 1 participant reported intentionally using background colors to encode and to retrieve items. The mean numbers of SC and DC items that this participant recalled were 4.5 and 4.5 , respectively, which shows an absence of a context effect.

\section{Discussion}

Experiment 2 successfully replicated the pattern of results for background-color context effects that was found in Experiment 1. (1) An item-by-item change of two background colors produced context effects in free recall; (2) SC items were recalled neither first nor earlier; (3) responses in free recall were not clustered related to their background colors; (4) the effect size did not change with study time; and (5) the introspective questionnaires indicate that the background-color context effects are produced by unintentional processing. These results clearly confirm the reliability of the pattern of these phenomena.

Additionally, the present results were replicated regardless of whether study time was confounded with context familiarity (Experiment 1 and the first list of Experiment 2) or not (the second list of Experiment 2).

\section{EXPERIMENT 3}

Experiment 3 examined whether background color produces context effects in free recall in the condition in which TBR items (but not so many as to lead to cue overload) are presented against one common background color. Previous studies have found no effects of background color when TBR items are presented against one common background color (Dulsky, 1935; Petrich \& Chiesi, 1976; Pointer \& Bond, 1998; Rutherford, 2004). As discussed before, it is still unclear whether such null effects were caused by cue overload, the persistence of one background color, or both.

Table 4

Number of First Responses and Mean Output Percentile in Free Recall for Same-Color and Different-Color Conditions As a Function of Context $\times$ Presentation Rate (in Seconds/Item) $\times$ List in Experiment 2

\begin{tabular}{|c|c|c|c|c|c|c|c|c|}
\hline \multirow[b]{4}{*}{ Presentation Rate } & \multicolumn{8}{|c|}{ List } \\
\hline & \multicolumn{4}{|c|}{ First } & \multicolumn{4}{|c|}{ Second } \\
\hline & \multirow{2}{*}{$\begin{array}{c}\text { Number of } \\
\text { First Responses }\end{array}$} & \multicolumn{3}{|c|}{ Output Percentile } & \multirow{2}{*}{$\begin{array}{c}\text { Number of } \\
\text { First Responses }\end{array}$} & \multicolumn{3}{|c|}{ Output Percentile } \\
\hline & & $M$ & $S D$ & $n$ & & $M$ & $S D$ & $n$ \\
\hline \multicolumn{9}{|l|}{$1.5 \mathrm{sec} /$ item } \\
\hline Same & 12 & 48.4 & 9.3 & 20 & 11 & 53.5 & 11.4 & 20 \\
\hline Different & 8 & 54.3 & 12.9 & 19 & 9 & 49.4 & 16.4 & 18 \\
\hline \multicolumn{9}{|l|}{$3.0 \mathrm{sec} /$ item } \\
\hline Same & 10 & 51.6 & 12.1 & 20 & 9 & 47.5 & 13.5 & 20 \\
\hline Different & 10 & 54.6 & 14.6 & 20 & 11 & 52.6 & 13.1 & 20 \\
\hline
\end{tabular}


Table 5

Observed and Expected Values of Context Repetitions in Free Recall As a Function of Presentation Rate $\times$ List in Experiment 2

\begin{tabular}{cccccc}
\hline & \multicolumn{4}{c}{ List } \\
\cline { 2 - 3 } & \multicolumn{2}{c}{ First } & & \multicolumn{2}{c}{ Second } \\
\cline { 2 - 3 } \cline { 5 - 6 } Presentation Rate & $M$ & $S D$ & & $M$ & $S D$ \\
\hline 1.5 sec/item & & & & \\
Observed & 2.60 & 1.16 & & 2.55 & 1.28 \\
Expected & 2.89 & 1.14 & & 2.77 & 1.15 \\
3.0 sec/item & & & & \\
Observed & 4.55 & 2.06 & & 3.55 & 1.36 \\
Expected & 4.22 & 1.32 & & 3.65 & 1.14 \\
\hline
\end{tabular}

Furthermore, it is possible that the previous null effects were due to methodological problems. For example, the context effect might have been eliminated by explicit cues in the paired-associate paradigm (Dulsky, 1935; Petrich \& Chiesi, 1976) or in the recognition paradigm (Rutherford, 2004), and/or by associative processing in the paired-associate paradigm (Dulsky, 1935; Petrich \& Chiesi, 1976). Additionally, the range of background colors (light yellow and white) that were used by Pointer and Bond (1998), and which failed to find background-color context effects without any explicit cues, might have been too small to produce context effects.

Experiment 3 used an uncued free-recall paradigm, as was used in Experiments 1 and 2, instead of a pairedassociate or recognition paradigm. We manipulated the background colors not only by hues but also by brightness, such as dark red and light green, and also correspondingly varied the foreground colors of the TBR items (white letters against a dark background color or black letters against a light background color).

\section{Method}

Design. A $2 \times 2$ mixed factorial design was used. The first factor was context (SC or DC) as a within-subjects factor. The second was presentation rate ( 3 or $6 \mathrm{sec} /$ item) as a between-subjects factor.

Participants. The participants were 32 undergraduates enrolled in an introductory psychology course at Shizuoka University, Hamamatsu, Japan, and 32 undergraduates enrolled in a developmental psychology course at Shizuoka Prefectural University, Shizuoka, Japan. None had participated in either Experiments 1 or 2. They received extra course credit for their participation. They were randomly assigned to one of the two between-subjects conditions. The 3 -sec condition consisted of 16 Shizuoka University and 16 Shizuoka Prefectural University undergraduates, and the 6-sec condition consisted of 16 Shizuoka University and 16 Shizuoka Prefectural University undergraduates.

Materials. Sixty Japanese two-letter words, whose association values (Hayashi, 1976) were not less than 90, were selected to be unrelated to each other. The 60 words were randomly assigned to four TBR lists, so that each list consisted of 15 unrelated words.

Context. The match or mismatch between the background colors of the TBR items at the study and test times were systematically varied between the lists as context. Two of the four TBR lists were randomly assigned to the SC condition, and the other two were assigned to the DC condition. The presentation order of the SC and DC lists was counterbalanced; half of the participants received the lists in "SC DC DC SC" order, and the other half received the lists in "DC SC SC DC" order. This order was intended to avoid confounding of the context condition and proactive interference across lists (see, e.g., Craik \& Birtwistle, 1971).
Three pairs of background colors were used: dark red and light green, dark blue and light yellow, and dark purple and light blue. Two pairs were randomly selected from the three pairs for the DC condition. One light color within one of the DC pairs was presented at study, and the dark color within the pair was presented at test. Additionally, one dark color within the remaining DC pair was presented at study, and the light color within the pair was presented at test. The remaining pair was split up and the colors were used for the two SC lists. Each of the two colors was presented as a background color both at study and test. For all conditions, the foreground colors of items were either white against dark background colors or black against light background colors.

Procedure. All the participants individually participated in the 15-min experiment. They received four TBR lists. The TBR items on each list were presented one-by-one at a rate of $3 \mathrm{sec}$ (exposure time was $2.5 \mathrm{sec}$ ) or $6 \mathrm{sec}$ (exposure time was $5.5 \mathrm{sec}$ ) per item on a 17-in. computer screen in 72-point MS-Gothic font. Participants were required to study the items and were also told that it was not necessary to remember the background color of each item. After each list presentation, participants were required to orally recall the list in any order. A 30 -sec counting task was imposed between each list presentation and test, as had occurred in Experiments 1 and 2. The presentation order of items within lists was determined at random across participants. A $10-\mathrm{sec}$ break was imposed between the lists.

\section{Results}

A $2 \times 2 \times 2$ (context $\times$ presentation rate $\times$ university) ANOVA was computed. The main effect of presentation rate was significant $\left[F(1,60)=30.16, M S_{\mathrm{e}}=7.03, p<\right.$ $.001]$, but neither the main effect of context $(F<1)$ nor the interaction of presentation and context $(F<1)$ was significant. Neither the main effect of university nor the interactions involving university were significant $\left(F_{\mathrm{S}}<1\right)$. Table 6 shows the mean number of items recalled as a function of context $\times$ presentation rate. On the questionnaire, participants reported having looked at the computer screen for most of the test period. Only 1 participant reported intentionally using background colors to encode and to retrieve items. The mean numbers of SC and DC items that this participant recalled were 6.0 and 6.5 , respectively. First responses, mean output percentile, and context repetitions were not computed, because all recalled items were presented against the same background color.

\section{Discussion}

The results of Experiment 3 showed no context effects with a common background color for all of the items, for either of the presentation rates. These results are consistent with the findings of the previous studies (Dulsky, 1935; Petrich \& Chiesi, 1976; Pointer \& Bond, 1998; Rutherford, 2004). Note that the present results were obtained despite the list length being short enough to avoid cue overload. This finding may imply that not only cue overload but also

Table 6

Proportion of Items Recalled As a Function of Context $\times$ Presentation Rate in Experiment 3

\begin{tabular}{cccccc}
\multicolumn{3}{c}{ Presentation Rate in Experiment 3 } \\
\cline { 2 - 3 } & \multicolumn{4}{c}{ Context } \\
\cline { 2 - 3 } \cline { 5 - 6 } Presentation Rate & $M$ & $S D$ & & $M$ & $S D$ \\
\hline 3 sec/item & .411 & .099 & & .419 & .086 \\
6 sec/item & .546 & .122 & & .542 & .123 \\
\hline
\end{tabular}


an item-by-item change in background color determines the production of background-color context effects.

Experiment 3 manipulated the background-color context between subjects. In this manipulation, the study-test context matching is confounded with the context familiarity. At the time of the recall test, the SC participants received the background color that they had observed throughout the study period, whereas the DC participants received a new background color that they had not seen during the study period. The lack of a context effect in Experiment 3 logically indicates that neither study-test context matching nor context familiarity influence recall when a common background color is presented behind all of the items. In addition, Experiment 2 showed that context familiarity would not influence recall, even if the background colors changed item-by-item. Smith (1979) also demonstrated that place context familiarity does not influence recall. In conclusion, the results of Experiments 2 and 3, along with Smith's (1979) results, imply that background-color context familiarity does not influence recall.

\section{EXPERIMENT 4}

Experiment 4 attempted to replicate and expand the results of Experiment 3, in which no context effects were found with a common background color for all items, by using a within-subjects manipulation of the backgroundcolor context instead of the between-subjects manipulation that was used in Experiment 3. The within-subjects manipulation can avoid the confounding between studytest context matching and context familiarity. Moreover, the within-subjects manipulation has another significance. In the within-subjects manipulation, there is no common background color for all the TBR items, because at least two colors must be presented. The condition used in Experiment 4 , therefore, is that many successive items are presented against one common color, instead of all of the items being presented against one common color, as had occurred in Experiment 3.

Additionally, there is at least one change from one background color to the other in the within-subjects manipulation. The first background color immediately after the change may attract intentional or unintentional processing more than the following ones. If so, the item presented against the first background color may show a context effect. To test this possibility, Experiment 4 analyzed recall performance across the serial positions within the same successive background color.

\section{Method}

Design. A $2 \times 5$ within-subjects design was used. The first factor was context (SC or DC), and the second factor was serial position within the five successive items against the same background color $(1,2,3,4$, or 5$)$.

Participants. The participants were 26 undergraduates enrolled in an introductory psychology course at Shizuoka University, Hamamatsu, Japan. None had participated in Experiments 1, 2, or 3. They received extra course credit for their participation.

Materials. The TBR list consisted of 22 unrelated Japanese twoletter words whose association values (Hayashi, 1976) were not less than 90 .
Background color. A pair of background colors was randomly selected from the two pairs of colors used in Experiments 1 and 2.

Procedure. TBR items were presented one-by-one at a rate of $2.0 \mathrm{sec} /$ item (exposure time was $1.5 \mathrm{sec} / \mathrm{item})$. Twenty items were randomly selected from the TBR list. The 20 items consisted of four sets of five successive items. The first and third sets were presented against the same color that was randomly selected from the background-color pair, and the second and fourth sets were presented against the other color of the pair. Preceding the first set presentation, two more items were presented one-by-one at a rate of $2.0 \mathrm{sec} / \mathrm{item}$. These two items were not included in the data analysis. The background color of the first of these two items was the same as the color of the first and third sets, and the color of the second item was the same as the color of the second and fourth sets. In summary, the sequence of background colors was "ABAAAAABBBBBAAAAABBBBB." "A" or "B" refers to the background color for each item. There were two reasons for this insertion of two items before the 20 TBR items. One was to insert a different background color before the first set of items in order to make the color change comparable to that of the second and the fourth sets. The other was to equate the number of presentations of the two background colors. Otherwise, the procedure was identical to that of Experiment 1.

\section{Results}

Table 7 shows the mean number of items recalled as a function of context $\times$ serial position. A $2 \times 5$ (context $\times$ serial position) ANOVA was computed. Neither the main effects of context and serial position nor their interaction was significant $\left(F_{\mathbf{S}}<1\right)$.

The numbers of first responses in free recall for the $\mathrm{SC}$ and DC conditions were 14 and 12, respectively. The difference in the number of first responses between the $\mathrm{SC}$ and DC conditions was not significant $\left[\chi^{2}(1)=0.15\right.$, $p>$.60]. The mean output percentile and standard deviation for the SC condition were 48.6 and 10.8 , respectively, and those for the DC condition were 50.3 and 10.4, respectively. The sample sizes were 26 for the SC condition and 25 for the DC condition, because 1 DC participant recalled only SC items. The difference in the mean output percentile between the SC and DC conditions was not significant $(t<1)$.

Furthermore, the observed and expected values of context repetitions in recall were 3.08 and 3.41, respectively. The difference between the observed and expected values of context repetitions was not significant $[t(25)=1.31$, $\left.M S_{\mathrm{e}}=0.25, p>.10\right]$. On the questionnaire, the participants reported having looked at the computer screen for most of the test period. No participant reported intentionally using background colors to encode or to retrieve items.

Table 7

Proportion of Items Recalled As a Function of Context $\times$ Serial Position in Experiment 4

Context

\begin{tabular}{|c|c|c|c|c|}
\hline \multirow[b]{3}{*}{ Serial Position } & \multicolumn{4}{|c|}{ Context } \\
\hline & \multicolumn{2}{|c|}{ Same } & \multicolumn{2}{|c|}{ Different } \\
\hline & $M$ & $S D$ & $M$ & $S D$ \\
\hline 1 & .462 & .337 & .404 & .311 \\
\hline 2 & .308 & .369 & .308 & .342 \\
\hline 3 & .327 & .365 & .327 & .338 \\
\hline 4 & .308 & .342 & .365 & .406 \\
\hline 5 & .385 & .288 & .327 & .365 \\
\hline Combined & .344 & .166 & .341 & .210 \\
\hline
\end{tabular}




\section{Discussion}

The results of Experiment 4 show no context effect when five successive items were presented against the same background color. These results replicated and extended the findings of Experiment 3 and those of previous studies that found no context effect when all the TBR information was presented against only one common background color (Dulsky, 1935; Petrich \& Chiesi, 1976; Pointer \& Bond, 1998; Rutherford, 2004). The results of Experiment 4 imply that a necessary condition for eliminating the background-color context effect is not a common background color for all TBR items, but only a number of successive repetitions of the same background color.

Furthermore, if successive repetitions of the same background color were eliminated, or had at least diminished the context effect, then the item presented in the first few serial positions within a set of the same background color would reveal the context effect, and this effect would decrease as a function of the serial position. Although visual inspection suggests that the first and last serial positions show slight context effects, this impression was not supported statistically. Even though the item in the first serial position might be more distinctive at encoding, it might be buried in the mass of items with the same background color at retrieval. To clarify this, further research is needed.

Finally, the results for the first response, mean output percentile, and context repetitions successfully replicated the results of Experiments 1 and 2. SC items were not recalled first or earlier, and responses in free recall were not clustered in relation to their background colors. Note that Experiment 4 used a blocked presentation of background colors, which is reported to enhance clustering more than a random presentation (see, e.g., Cofer, Bruce, \& Reicher, 1966), which was used in Experiments 1 and 2.

\section{GENERAL DISCUSSION}

The present experiments have demonstrated that an item-by-item change in background colors is necessary and sufficient to produce context effects. A simple item-by-item change of two background colors produced a significant context effect (Experiments 1 and 2), whereas a common background color for a number of successive items did not (Experiments 3 and 4). Previous research has demonstrated that a unique background color for every item produces background-color context effects in paired-associate studies (Dulsky, 1935; Weiss \& Margolius, 1954). However, the present finding indicates that a unique background color for every item is not necessary for producing context effects in free recall; rather, a simple change of two colors is sufficient to produce a background-color context effect in free recall.

Furthermore, the present experiments have demonstrated that the background-color context effect was eliminated by the persistence of one background color. Previous research and the present Experiment 3 indicate that a common background color for all the items of a list does not produce a background-color context effect (Experiment 3; Dulsky, 1935; Petrich \& Chiesi, 1976; Pointer \& Bond, 1998; Rutherford, 2004). Furthermore, the present
Experiment 4 indicates that a common background color for a number of successive items is sufficient to eliminate the background-color context effect. More importantly, this elimination of the background-color context effect was found even when the background-color context cues were not overloaded (Experiments 3 and 4). Thus, the present study adds an item-by-item change in background colors to the determinants of the background-color context effect.

The persistence of one background color may make participants inattentive or habituated to the color. An item-by-item change in background colors may attract attention to or dishabituate the colors, even if the change is a simple change of two colors, as was the case in Experiments 1 and 2. Habituation can better explain the present findings than can inattention. The results of the questionnaire indicate that unintentional processing produces the background-color context effects. Unintentional processing is subject to habituation, but not to inattention. Furthermore, a similar phenomenon, in which the persistence of a simple visual context eliminates context effects on perceptual-motor learning, is also explained by habituation (Dibbets, Maes, Boermans, \& Vossen, 2001).

Moreover, the present experiments unanimously showed that (1) SC items were recalled neither first nor earlier, and (2) responses in free recall were not clustered by their background colors. These results indicate that items within the list did not compete or were not related to each other in recall; rather, each item was retrieved individually in relation to its own background-color cue. This result further implies that background-color context effects are not produced by a one-to-many relationship between one background color and a set of items presented with the color, but instead by a one-to-one relationship between each item and its own background color.

The present findings imply that background-color context has different functions from the other types of EC, such as place, background music, and odor. At the time of encoding, an item-by-item change in background color is necessary for producing context effects, whereas the other ECs can produce context effects with the total list of items (see, e.g., Balch et al., 1992; Cann \& Ross, 1989; Smith, 1988). At the time of retrieval, background-color context cannot cue a list or sublist consisting of five or more items; it only cues each corresponding item individually. In contrast, place context can cue a whole list of items so that the items within the list are related and/ or compete with each other, as was previously described. Unfortunately, the relationship and competition among responses in free recall have not yet been clarified for ECs other than place context.

This functional difference may relate to a difference in the generality of contextual association. Contexts can be classified in terms of associative generality. One type of context can associate with a limited number of elements of an event because it changes relatively quickly; this is called local context (Glenberg, 1979). Another type of context can associate with all the elements of an event, because it typically remains stable or changes very slowly during the event; this is called global context (Glenberg, 
1979). According to this classification, Smith and Vela (2001) distinguished global or slow-changing contexts from fast-changing - and, hence, nonglobal-contexts, such as background-color context (see, e.g., Weiss \& Margolius, 1954) and simple-visual context (e.g., Murnane \& Phelps, 1993, 1994, 1995). They excluded the fast-changing contexts from their meta-analysis of ECdependent memory. Furthermore, Rutherford (2004) proposed a distinction between global EC (e.g., room) and local EC (e.g., background color). Theoretically, both Smith and Vela (2001) and Rutherford (2004) proposed that the global or slow-changing ECs and the local or fastchanging ECs are functionally different. The present study provides empirical evidence supporting this distinction.

The size of the background-color context effect in free recall did not change as a function of study time, regardless of whether context familiarity increased with study time (Experiment 1) or did not (Experiment 2). This result that the effect size of background-color context does not change with study time is reliable, because this pattern was found in Experiment 1, was replicated in Experiment 2 , and is consistent with the findings obtained with a recognition discrimination measure (Isarida et al., 2005; Isarida \& Ozeki, 2005). Furthermore, this pattern is the same as that for background-music context (Isarida \& Isarida, 2005), but different from that for place context (Isarida, 2005). Unfortunately, the pattern of change is still unclear for odor and other contexts.

This finding that effect size did not change with study time may imply that background-color context is processed independently of item processing. This is because the amount of processing of items did not influence the size of the context effects. However, if the processing of item and context were completely independent, the context would facilitate only simple recognition measured by hits and false alarms, but not recall or recognition discrimination measured by $d^{\prime}, A^{\prime}$, and CRS (hit rate minus false alarm rate). Context effects for simple recognition and for recognition discrimination may be produced through different processes. According to the ICE theory (Murnane, Phelps, \& Malmberg, 1999), the simple-visual context effect for simple recognition reflects only context familiarity (completely independent of item strength), but not relationships between items and their context. In contrast, recognition discrimination would reflect certain relationships between items and their context, such as an association or ensemble in the ICE theory. Also, recall should reflect certain relationships between items and their context. If there were no relationships between items and their context, the context would not facilitate recall of items.

If context effects in recall and recognition discrimination reflect certain relationships between items and context, then it is likely that contextual effect size increases as a function of the length of time items are processed within the context. In the present experiments, the effect size of background-color context did not increase as a function of study time. In the case of background-color context, once item and context are processed contiguously, they might associate with almost maximum strength, as in Guthrie's classic theory (Guthrie, 1935). Otherwise, the associative strength may increase slowly with the time for which items are presented within the context, even if items and context are associated. In contrast, the effect size of place context markedly increases with the determinants of item strength. Isarida manipulated $\mathrm{EC}$ by the combination of place, task, and experimenter, and found that the size of the EC effects significantly increased with study time (Isarida, 2005) and the number of rehearsals (Isarida, 1992).

These findings imply that there is another difference in contextual functions between background-color context and place context. This result may suggest another distinction of ECs in addition to the distinction between local and global ECs. This functional difference can be explained by assuming that information directly associated with the background-color context is different from that associated with the place context. Each background color can associate with each corresponding TBR item by contiguity. A background color provides a field in which an item appears and must change item-by-item to produce a context effect. As a result, a one-to-one relationship could be formed between a background color and a single corresponding item. In contrast, a place may associate with an experimental event rather than each TBR item. A place provides a field in which an experimental event occurs, and exists throughout the event. As a result, an association could be formed between a place and an experimental event including a set of items. Of course, a place can - at least indirectly - be associated with TBR items because the items are embedded within the event.

In summary, the present study provides empirical evidence that background colors do not function as a global EC, but as a local EC. First, background colors can produce context effects in free recall when they simply change item-by-item, but they do not when one common background color is presented for a number of successive items. Second, the responses in free recall are not related or competing with each other in terms of background colors. Thus, the contextual function of background color is different from that of other global ECs, such as place, background music, and odor. Furthermore, the present study demonstrates that the effect size of backgroundcolor context in free recall does not change with study time. This finding suggests that the contextual function of background color is the same as that of background music, but is different from that of place. Because various ECs may have the same or different functions, it is necessary to classify the characteristics of respective ECs empirically to clarify the mechanisms of episodic memory.

\section{AUTHOR NOTE}

The authors thank M. G. Sheftall for his comments on an earlier version of this article. Portions of this research were reported at the 66th Annual Meeting of the Japanese Psychological Association, Tsukuba; at the 67th Annual Meeting of the Japanese Psychological Association, Hiroshima; and at the 4th Annual Meeting of the Japanese Society for Cognitive Psychology, Nagoya. Correspondence should be addressed to T. Isarida, Faculty of Informatics, Shizuoka University, 3-5-1 Johoku, Hamamatsu, 432-8011 Japan (e-mail: isarida@inf .shizuoka.ac.jp). 


\section{REFERENCES}

Balch, W. R., Bowman, K., \& Mohler, L. A. (1992). Music-dependent memory in immediate and delayed word recall. Memory \& Cognition, 20, 21-28.

CAnN, A., \& Ross, D. A. (1989). Olfactory stimuli as context cues in human memory. American Journal of Psychology, 102, 91-102.

Cofer, C. N., Bruce, D. R., \& Reicher, G. M. (1966). Clustering in free recall as a function of certain methodological variations. Journal of Experimental Psychology, 71, 858-866.

Craik, F. I. M., \& Birtwistle, J. (1971). Proactive inhibition in free recall. Journal of Experimental Psychology, 91, 120-123.

Dibbets, P., Maes, J. H. R., Boermans, K., \& Vossen, J. M. H. (2001) Contextual dependencies in predictive learning. Memory, 9, 29-38.

Dougal, S., \& Rotello, C. M. (1999). Context effects in recognition memory. American Journal of Psychology, 112, 277-295.

DULSKY, S. G. (1935). The effect of a change of background on recall and relearning. Journal of Experimental Psychology, 18, 725-740.

Geiselman, R. E., \& BJork, R. A. (1980). Primary versus secondary rehearsal in imagined voices: Differential effects on recognition. Cognitive Psychology, 12, 188-205.

Geiselman, R. E., \& GlenNy, J. (1977). Effects of imagining speakers' voices on the retention of words presented visually. Memory \& Cognition, 5, 499-504.

Glenberg, A. M. (1979). Component-levels theory of the effects of spacing of repetitions on recall and recognition. Memory \& Cognition, 7, 95-112.

Godden, D. R., \& Baddeley, A. D. (1975). Context-dependent memory in two natural environments: On land and underwater. British Journal of Psychology, 66, 325-331.

Guthrie, E. R. (1935). The psychology of learning. New York: Harper.

Hayashi, T. (1976). New norms of nonsense syllables. Tokyo: Tokai University Press.

ISARIDA, T. (1989). Role of output interference on long-term recency effects. Japanese Journal of Psychology, 60, 24-30.

ISARIDA, T. (1992). Influences of environmental-context changes on rehearsal effects in episodic memory. Japanese Journal of Psychology, 63, 262-268.

IsARIDA, T. (2005). Study-time effect on free recall within and out of context. Memory, 13, 785-795.

ISARIDA, T., \& IsARIDA, T. K. (1999). Effects of contextual changes between class and intermission on episodic memory. Japanese Journal of Psychology, 69, 478-486.

IsARIDA, T., \& IsARIDA, T. K. (2004). Effects of environmental context manipulated by the combination of place and task on free recall. Memory, 12, 376-384.

IsARIDA, T., \& ISARIDA, T. K. (2005). Effects of presentation rate on background-music dependent memory. Paper presented at 3rd Annual Meeting of Japanese Society for Cognitive Psychology, Kanazawa.

IsARIDA, T., \& ISARIDA, T. K. (2006). Influences of environmental context on the recency effect in free recall. Memory \& Cognition, 34, 787-794.

IsARIDA, T., IsARIDA, T. K., \& OKAMOTO, K. (2005). Influences of cueoverload on background-color context effects in recognition. Japanese Journal of Cognitive Psychology, 3, 45-54.
IsARIDA, T., \& MorII, Y. (1986). Contextual dependence of the spacing effect in free recall. Japanese Journal of Psychology, 57, 20-26.

IsARIDA, T., \& OzEKI, K. (2005). Environmental context effects of background colors on recognition memory. Japanese Journal of Psychology, 75, 503-510.

Murnane, K., \& Phelps, M. P. (1993). A global activation approach to the effect of changes in environmental context on recognition. Journal of Experimental Psychology: Learning, Memory, \& Cognition, 19, 882-894.

Murnane, K., \& Phelps, M. P. (1994). When does a different environmental context make a difference in recognition? A global activation model. Memory \& Cognition, 22, 584-590.

Murnane, K., \& Phelps, M. P. (1995). Effects of changes in relative cue strength on context-dependent recognition. Journal of Experimental Psychology: Learning, Memory, \& Cognition, 21, 158-172.

Murnane, K., Phelps, M. P., \& Malmberg, K. (1999). Contextdependent recognition memory: The ICE theory. Journal of Experimental Psychology: General, 128, 403-415.

Petrich, J. A., \& Chiesi, H. L. (1976). The locus of color-context changes, encoding instructions, and their effect on retroactive inhibition. Journal of Experimental Psychology: Human Learning \& Memory, 2, 190-199.

Pointer, S. C., \& Bond, N. W. (1998). Context-dependent memory: Colour versus odour. Chemical Senses, 23, 359-362.

RAND, G., \& WAPNER, S. (1967). Postural status as a factor in memory. Journal of Verbal Learning \& Verbal Behavior, 6, 268-271.

RUTHERFORD, A. (2004). Environmental context-dependent recognition memory effects: An examination of ICE model and cue-overload hypotheses. Quarterly Journal of Experimental Psychology, 57A, 107127.

Smith, S. M. (1979). Remembering in and out of context. Journal of Experimental Psychology: Human Learning \& Memory, 5, 460-471.

Smith, S. M. (1985). Background music and context-dependent memory. American Journal of Psychology, 6, 591-603.

Smith, S. M. (1988). Environmental context-dependent memory. In G. M. Davies \& D. M. Thomson (Eds.), Memory in context: Context in memory (pp. 13-34). New York: Wiley.

Smith, S. M. (1994). Theoretical principles of context-dependent memory. In P. Morris \& M. Gruneberg (Eds.), Theoretical aspects of memory (2nd ed., pp. 168-195). New York: Routledge.

Smith, S. M., Glenberg, A., \& Bjork, R. A. (1978). Environmental context and human memory. Memory \& Cognition, 6, 342-353.

Smith, S. M., \& Vela, E. (2001). Environmental context-dependent memory: A review and meta-analysis. Psychonomic Bulletin \& Review, 8, 203-220.

WatKIns, O. C., \& WATKIns, M. J. (1975). Buildup of proactive inhibition as a cue-overload effect. Journal of Experimental Psychology: Human Learning \& Memory, 104, 442-452.

Weiss, W., \& Margolius, G. (1954). The effect of context stimuli on learning and retention. Journal of Experimental Psychology, 48, 318322 .

(Manuscript received December 6, 2005; revision accepted for publication January 2, 2007.) 